\title{
Graham Little-Lassueur Syndrome with Hypertrophic Lichen Planus in a Patient with Chronic Hepatitis C
} \author{
Luciana ${ }^{5}$, Mureșan Vasile Adrian ${ }^{5}$, Morariu Silviu Horia 6 \\ 1 Dermatology Clinic, County Hospital of Tîrgu Mureș, Romania, \\ 2 Department of Public Health and Medicines Management, Tîrgu Mureș, \\ 3 Dermatology Clinic, Emergency Military Hospital, Bucharest, Romania \\ ${ }_{4}^{4}$ Anesthesiology and Intensive Care medicine Clinic, Emergency County Hospital of Tîrgu Mureș \\ 5 University of Medicine and Pharmacy Tîrgu Mureș, Romania \\ ${ }^{6}$ Department of Dermatology, University of Medicine and Pharmacy Tîrgu Mureș, Romania
}

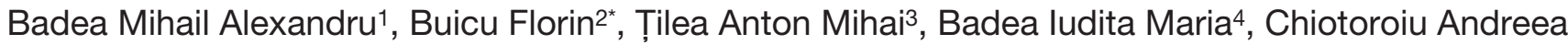

Graham Little-Lassueur Syndrome (GLLS) is considered a form of lichen planopilaris which associates follicular lichen planus, cicatricial alopecia of the scalp and noncicatricial alopecia of the axillary and/or pubic regions. We present the case of a 47 years old female patient, known for 5 years with chronic hepatitis $\mathrm{C}$ and a poor therapeutic control of the disease due to Interferon intolerance. She presented to our clinic for the occurrence on the shins of some well-defined, intensely pruritic erythematous plaques, covered with thick scales, with a verrucous appearance, accompanied by excoriations. The skin biopsy reveal hypertrophic lichen planus on the shins and lichen planopilaris on the scalp. The patient was treated with systemic antihystamines, topical corticosteroids and salicylic acid under occlusion, emollients, phototherapy UVB narrow band 4 sessions/week for 3 weeks, cryotherapy. From our knowledge this is the first case of GLLS associated with chronic viral hepatis $\mathrm{C}$.

Keywords: Graham Little Lassueur syndrome, hypertrophic lichen planus, chronic hepatitis C

Received 30 July 2015 / Accepted: 11 September 2015

\section{Introduction}

Graham Little-Lassueur Syndrome (GLLS) is considered a form of lichen planopilaris which associates follicular lichen planus, cicatricial alopecia of the scalp and noncicatricial alopecia of the axillary and/or pubic regions. It is a rare dermatosis, usually encountered in women between 30 and 60 years old. In most cases it starts with cicatricial alopecia of the scalp [1]. Lichen planus can be induced by the infection with the hepatitis $\mathrm{C}$ or $\mathrm{B}$ viruses. It seems that the viral particles are functioning as an antigen for the T lymphocytes leading to the occurrence of the cutaneous lesions [2].

\section{Clinical case}

We present the case of a 47 years old female patient, known for 5 years with chronic hepatitis $\mathrm{C}$ and a poor therapeutic control of the disease due to Interferon intolerance. She presented to our clinic for the occurrence on the shins of some well-defined, intensely pruritic erythematous plaques, covered with thick scales, with a verrucous appearance, accompanied by excoriations. The physical examination revealed, in the bilateral parieto-occicipital areas of the scalp, plaques of alopecia with skin atrophy, irregular borders and erythematous macules in the periphery. Hair loss started in 2011 in the occipital region, with a gradual expansion. A thorough examination discovered the presence in the bilateral axillary areas and the pubic region of alopecia with

* Correspondence to: Florin Buicu

E-mail: florin_buicu@yahoo.com the keeping of hair bulbs. The biopsy from a plaque on the right shin showed hyperkeratosis with orthokeratosis, acanthosis and elongated rete ridges. The inflammatory infiltrate, composed of lymphocytes and histiocytes, had a band-like distribution in the papillary dermis. A biopsy from the periphery of an alopecic plaque of the scalp showed hyperkeratosis, hypergranulosis alternating with hypogranulosis, acanthosis and a band-like lymphocytic infiltrate in the papillary dermis and around the hair follicles. The patient was treated with systemic antihystamines, topical corticosteroids and salicylic acid under occlusion, emollients, phototherapy UVB narrow band 4 sessions/ week for 3 weeks, cryotherapy. The peripheral areas of the scalp alopecic plaques were treated with intralesional corticosteroids. The evolution was favourable with an improvement of the general condition, significantly reduced itching and a decrease in the size and the inflammatory aspect of the lesions on the shins. The evolution of scalp alopecia was stationary (Figure 1,2).

\section{Discussions}

The association of these three types of lesions was first observed by Piccardi in 1914, who called it cheratosis pinulosa [3]. Graham-Little, Lassueur and Feldman further contributed to its description [3].

GLLS is a condition more common in women. It is quite rare in men and to our knowledge, less than 10 cases were reported so far in the literature. In 2012, Laszlo FG described a case in a male patient and also in a review of the literature found only seven cases [4]. Among these cases an 


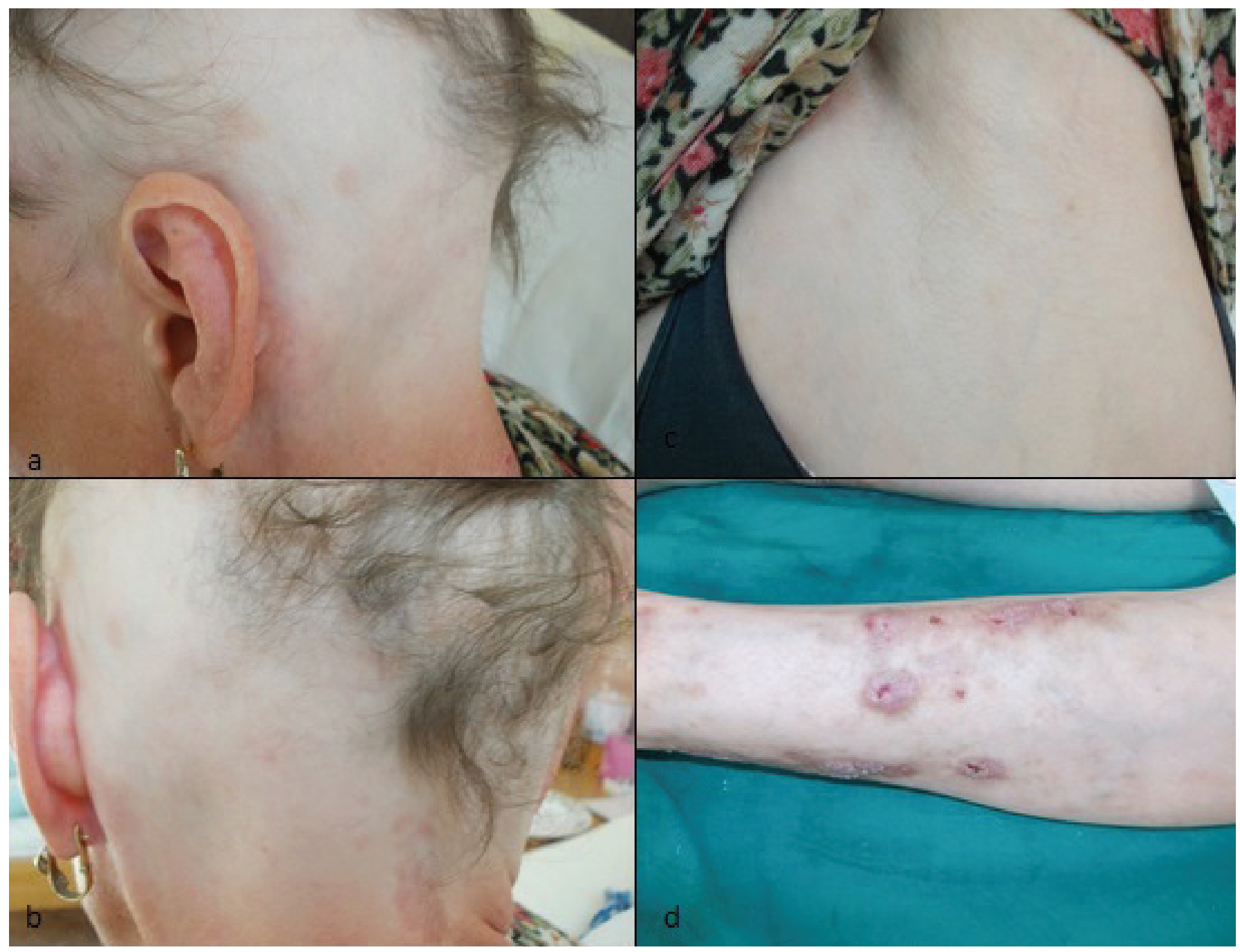

Fig 1. a, b: Cicatricial alopecia of the scalp; c: Noncicatricial alopecia of the axillary region; d: Hypertrophic Lichen Planus

interesting one was reported by Vega et al about a patient with GLLS and testicular feminization syndrome [5]. Approximately $50 \%$ of the patients present, during the evolution of the disease, various forms of cutaneous or mucosal lichen planus [6].

The association between lichen planus and the infection with hepatitis B and C viruses is well known, especially if the oral erosive form of lichen planus is present. This association was demonstrated by revealing the viral particles in the lichen planus lesions [2]. A GLLS case was described after vaccination against the hepatitis B virus [7]. To our knowledge there is no case described in the literature that associates GLLS with hepatitis $\mathrm{C}$ virus (HCV) chronic infection.

GLLS debuts in most cases with cicatricial alopecia of the scalp, which may precede other manifestations by years, being often diagnosed as pelade or pseudopelade of Brocq.

It is cited the frequent association of other forms of lichen planus during the evolution of typical and complete manifestations of GLLS [8]. In 2011 Vashi et al describes a patient with lichen planus pigmentosus, noncicatricial pubic alopecia and follicular lichen of the skin. The patient did not have cicatricial alopecia of the scalp. Abbas also describes a female patient with GLLS that had frontal fibrosing alopecia as a variant of cicatricial alopecia of the scalp. A case of ulcerated lichen planus was also described in a female patient with a 9 years history of GLLS [9].

Ghislain et al describe the appearance of GLLS in a patient with a 20 years history of classic lichen planus [10].

In 2013, Brar and his team describe lesions of hypertrophic lichen planus in a patient with GLLS [11].

A thorough examination did not revealed in our patient follicular lichen of the skin lesions. The patient also denied the presence of such lesions in the past medical history. A periodic follow-up is required in case the patient starts to develop lichen planopilaris lesions.

The treatment consists of topical or systemic corticosteroids, PUVA therapy, acitretin, cyclosporine $\mathrm{A}$, thalidomide, metronidazole, hydroxychloroquine, dapsone [12]. Due to the hepatic disease we excluded photohemotherapy (inability of the liver to metabolise 8-methoxypsoralen) and retinoids. We didn't use metronidazole either, due to the lack of studies on larger groups of patients. Even 

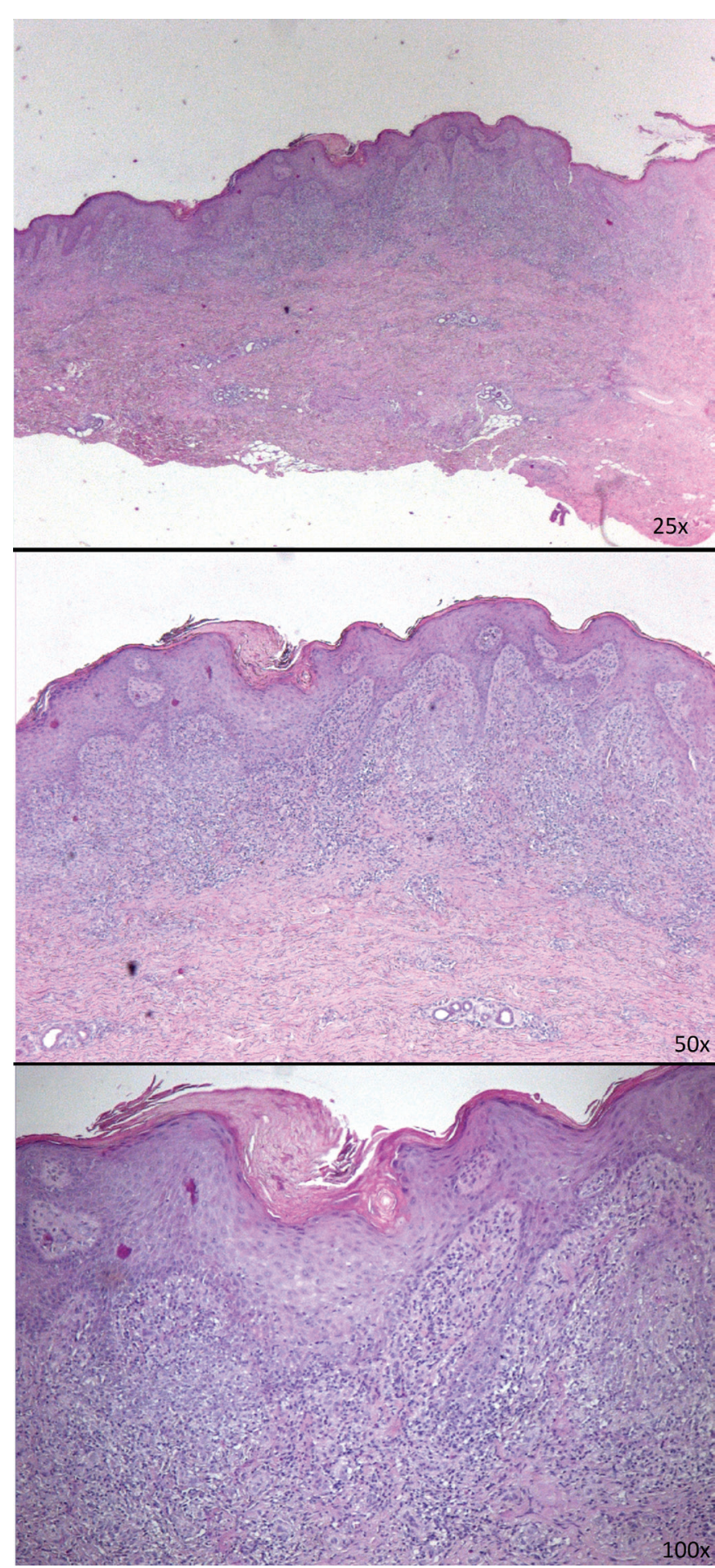

Fig. 2. Cutaneous biopsy aspect: hyperkeratosis with orthokeratosis, acanthosis and elongated rete ridges, inflammatory infiltrate, composed of lymphocytes and histiocytes, had a band-like distribution in the papillary dermis though at doses of $500 \mathrm{mg} \mathrm{x} 2$ / day for 8 weeks was cited as having a very good efficacy, theside effects included liver involvement. Cyclosporin A has somebeneficial effect on the development of alopecia however it is only effective when administered early [13].

The patient is followed regularly in our clinic and the disease is stationary. If during the evolution of the syndrome new lesions of follicular lichen or of other type will appear, we will complete the description of our case in a later review.

\section{Conclusions}

GLLS is a complex dermatosis, in which the classical lesions do not always occur simultaneously. The syndrome can be associated with different forms of lichen planus and can also be associated with HCV chronic infection.

\section{References}

1. Bucur G, Opriș DA. Bolidermatovenerice - enciclopedie (Dermatovenerological Diseases-Encyclopaedia) , p. 742, 2nd edition. Bucharest, National Medical Publishing House, 2002.

2. Pablo L, Javier O, Javier B, et al. Detection of Hepatitis C Virus RNA and Core Protein in Keratinocytes from Patients with Cutaneous Lichen Planus and Chronic Hepatitis C. Journal of Investigative Dermatology. 2002;119:798-803.

3. Zegarska B, Kallas D, Schwartz R A. Graham-Little syndrome. Acta Dermatoven APA. 2010;19(3):39-42.

4. Laszlo GF. Graham-Little-Piccardi-Lasseur syndrome: case report and review of the syndrome in men. Int J Dermatol. 2014;53(8):1019-1022.

5. Vega Gutiérrez J, Miranda-Romero A, Pérez Milán F et al. Graham LittlePiccardi-Lassueur syndrome associated with androgen insensitivity syndrome (testicular feminization). J EurAcadDermatolVenereol. 2004;18(4):463-436.

6. Lindmaier A, Jurecka W. Lichen ruberulcerosus. Differentiation from Graham-Little syndrome.Pathogenesis and therapy. Z Hautkr. 1988;63(5):439-443.

7. Bardazzi F, Landi C, Orlandi C et al. Graham Little-Piccardi-Lasseur Syndrome Following HBV Vaccination. ActaDermatoven APA. 1999;79(1):93

8. Abbas O, Chedraoui A, GhosnS.Frontalfibrosing alopecia presenting with components of Piccardi-Lassueur-Graham-Little syndrome. J Am AcadDermatol. 2007;57(2 Suppl):15-18.

9. Vashi N, Newlove T, Chu J et al. Graham-Little-Piccardi-Lassueur syndrome. Dermatol Online J. 2011;17(10):30.

10. Ghislain PD, Van Eeckhout P, Ghislain E. Lassueur-Graham Little-Piccardi syndrome: a 20-year follow-up. Dermatology. 2003;206(4):391-392.

11. Brar BK, Khanna E, Mahajan BB. Graham Little PiccardiLasseur Syndrome: A Rare Case Report with Concomitant Hypertrophic Lichen Planus. Int J Trichology. 2013;5(4):199-200.

12. Baibergenova A, Donovan J. Lichen planopilaris: update on pathogenesis and treatment. Skinmed. 2013;11(3):161-165.

13. Bianchi L, ParoVidolin A, Piemonte P. Graham Little-Piccardi-Lassueur syndrome: effective treatment with cyclosporin A. Clin Exp Dermatol. 2001;26(6):518-520. 